\title{
A new type of problem to stabilize an assembly setup
}

\author{
Dilip Roy $^{\mathrm{a}^{*}}$ and Debdip Khan ${ }^{\mathrm{b}}$
}

${ }^{a}$ Department of Business Administration, The University of Burdwan, Burdwan, W.B., India

${ }^{b}$ Department of Business Administration,Burdwan Raj College, Burdwan, W.B., India

\begin{tabular}{ll}
\hline A R T I C L E I N F O & A B S T R A C T \\
$\begin{array}{l}\text { Article history: } \\
\text { Received January } 102010\end{array}$ Accepted 5 April 2011 & $\begin{array}{l}\text { Traditional assembly lines are still attractive means of mass and large-scale series production. } \\
\text { Previous research works mainly dealt with the minimization of balancing loss, subject to } \\
\text { Available online }\end{array}$ precedence constraints. Very recently the focus of attention shifted towards system loss. \\
8 April 2011 & $\begin{array}{l}\text { However, these losses are not the proper indicators of the stability of the system since the } \\
\text { efficiency of the assembly line increases normally when the stability of the system increases. In } \\
\text { Keywords: } \\
\text { Balancing loss }\end{array}$ this paper, we introduce a new type of assembly line, which is totally different form the existing \\
System loss & types of assembly line studied in the literature. In this work, we define the stability of the \\
Reliability & system in terms of reliability of the assembly line. The objective is to design an assembly line \\
Slackness & with a desired level of working stability measured through this reliability measure. This special \\
Mixed integer programming & type of assembly line, where production rate can be increased by minimizing the cycle time \\
Stochastic constraints & subject to a given level of reliability and precedence constraints, extends the decision-making \\
SALBP-3 & framework available in the literature on assembly line balancing problem and indirectly takes \\
& care of both balancing loss and system loss.
\end{tabular}

(c) 2011 Growing Science Ltd. All rights reserved.

\section{Introduction}

Assembly Line method is a popular and important technique in production involving high volume. In view of its low cost production, it has gradually replaced with traditional production methods. The importance of mass production to ensure overall cost leadership has encouraged researchers to work on the problem of arriving at an optimum balancing solution. At an earlier stage, Bryton (1954) addressed this problem from an analytical angle. The linear programming approach, to arrive at an optimum solution for this problem, was introduced by Salveson (1955) and Bowman (1960). Thereafter, the heuristic methods came as may be seen from the works of Kilbridge and Wester (1961). Helgerson and Birnie (1961), Moodie and Young (1965) and Mansoor (1968) worked on the heuristic ranked positional weight technique for solving an assembly line balancing problem. Charlton and Death(1969) suggested a general method for machine scheduling. Nevins (1972) used best bud search and Grabau et al. (1997) used simulation method to generate the data to balance an assembly line. 
Hoffman (1963), Mansoor and Yadin (1971) and Geoffrion (1976) used mathematical programming approach to present an analytical formulation of the problem and arrive at the solution. Graves and Lamer (1983) introduced integer programming procedure for designing an assembly system. Suhail (1983) optimized conveyor-paced assembly line system. Sarin and Erel (1990) developed a cost model for the single-model stochastic assembly line balancing problem for minimizing the total labor cost. Berger et al. (1992) adopted Branch-and-Bound algorithm for the multi-product assembly line balancing problem. Suresh and Sahu (1994) addressed simulated annealing for assembly line balancing problem. Amasaka and Sakai (1996) improved the reliability of body assembly line equipment. The branch and cut approach was used by Pinnoi and Wilhelm (1998) to deal with the problem of system design. Nicosia et al. (2002) suggested a different type of optimization procedure for optimally balancing assembly lines with different workstations. Erel et al. (2005) addressed beam search-based method for the stochastic assembly line balancing problem in U-lines. Zhao et al. (2006) dealt with sequence-to-customer goal with stochastic demands for a mixed-model assembly line for minimizing the number of stations. Bukchin and Rabinowitch (2006) proposed a branch-and-bound based solution. Gu et al.(2007) made an attempt to solve assembly line balancing problem by estimation of distribution. Chernyi (2007) analyzed probabilistically the performance of a synchronous assembly line. Agarwal and Tiwari (2008) described a collaborative ant colony algorithm to stochastic mixed-model U-shaped disassembly line balancing and sequencing problem. Gamberini et al. (2009) proposed a multiple single-pass heuristic algorithm for solving the problem of stochastic assembly line rebalancing. Roy and Khan (2010) addressed the problem of system loss and suggested a generic approach for designing of an assembly line where, with a given number of workstations, one can efficiently arrive at the desired solution under different methods of search like simulation, heuristic etc. Roy and Khan (2011a) also optimized the assembly line balancing problem by using a stochastic programming approach.

\section{Problem description}

It may be noted that, the balancing problems studied in all previous studies are oriented towards minimization of balancing loss and in later phase on system loss. However, minimization of balancing loss and system loss will not ensure the stability of the system, which is very important for any production system. For example, if one can construct an assembly line perfectly balanced in the sense that cycle time exactly matches with the workstation time for each workstation then the balancing loss will be zero. The system loss was already measured in terms of variance of idle times (see Roy and Khan, 2010) or in terms of range of idle time (see Roy and Khan, 2011b). However, under human elements involved in the production process, the chance of functioning of such a system will be very low. For example, for any symmetric distribution, the chance of completion of the work in any workstation is half and the chance that the system works is $\left(\frac{1}{2}\right)^{N}$ where $N$ is the number of workstations. As $N$ increases, that probability tends to zero indicating extreme instability in the system. To our mind, stability should be a major consideration and this stability must be measured in terms of system reliability. The concept of system reliability of an assembly line is a completely different concept, independent of different types of losses involved in an assembly line and independent of the concept of product reliability.

Our objective in this current work is to design an assembly line, which will be very reliable and hence very stable. Accordingly, we define a new type of assembly line balancing problem. Corresponding solution procedure is introduced in terms of an algorithm and demonstrated through an example. This problem is a markedly different problem as it extends the classification system of the assembly line problem as given in Scholl (1999). We propose to refer it as a new variant of SALBP and define it as Type-3 simple assembly line balancing problem (SALBP-3) where the main focus is on the reliability of the system. The objective of SALBP-3 is to maximize the rate of production maintaining a desired level of reliability for the setup without violating the precedence constraints. In other words, one minimizes the cycle time c under precedence constraints and a given level of reliability. The existing 
variants of SALBP minimizes the number of workstations $N$ given a cycle time $c$ under type 1 and minimizes the cycle time $c$ given the number of workstations $N$ under type 2 problems.

\subsection{Notation}

a(i,j) binary measure taking value 1 under assignment of task i to workstation $\mathrm{j}$ and 0 otherwise,

B balancing loss

C cycle time

$\mathrm{C}_{\min } \quad$ minimum cycle time for a given $\mathrm{K}$

$\mathrm{C}_{\mathrm{t}} \quad$ trial cycle time

$\mathrm{E}($.) statistical expectation operator

G(p) gamma distribution with mean $p$

$\mathrm{K}$ number of jobs

$\mathrm{L}_{\mathrm{j}} \quad$ variable idle time of $\mathrm{j}^{\text {th }}$ work station (necessarily nonnegative)

$\mathrm{N}$ number of workstations

$\mathrm{N}_{\text {min }}$ minimum number of workstation for a given cycle time

$p_{i} \quad$ expected task time of $\mathrm{i}^{\text {th }}$ job

Pr.[E] probability of an event E

$\mathrm{R}_{\mathrm{AL}} \quad$ reliability measure for the entire assembly line

$R_{j} \quad$ reliability of the $j^{\text {th }}$ workstation

$\mathrm{S}_{\mathrm{t}} \quad$ slackness for trial cycle time $\mathrm{c}_{\mathrm{t}}$, i.e., $\mathrm{S}_{\mathrm{t}}=\mathrm{c}-\mathrm{c}_{\mathrm{t}}$

$\mathrm{t}_{\mathrm{i}} \quad$ independent and random task time or assembly time of $\mathrm{i}^{\text {th }}$ job

$\mathrm{W}_{\mathrm{j}} \quad \mathrm{j}^{\text {th }}$ workstation

$\boldsymbol{\Gamma}(\mathrm{p}, \mathrm{c})$ incomplete gamma function up to point c, corresponding to the parameter p

\subsection{Methodology}

Balancing loss offers a measure of the efficiency of an assembly line. In the deterministic setup it is defined as the loss resulting from allocation of work elements to workstations and is given by

$$
B=\left\{\left(N C-\sum_{i=1}^{K} T_{i}\right) / N C\right\} .100 \% .
$$

In the stochastic setup, time elements are replaced by their expected times because under the stochastic setup the balancing loss itself becomes a random variable. Over the years, the basic consideration for designing any assembly line has always been the balancing loss, B. However, this measure alone is not sufficient to ensure efficiency of the production system. There must be some consideration for ensuring high chance of meeting the cycle time requirements for each workstation. We propose to have a measure for the same in terms of the reliability of $\mathrm{j}^{\text {th }}$ workstation, $\mathrm{R}_{\mathrm{j}}$, defined as $R_{j}=\operatorname{Pr}\left[L_{j} \geq 0\right]$ where $L_{j}$ is the variable idle time in the in the $\mathrm{j}^{\text {th }}$ workstation. Conceptually, the assembly line can be viewed as an arrangement of $N$ workstations in series in the sense if one workstation fails to meet the cycle time requirement the assembly line itself faces operational failure. Since elemental times are independently distributed, work station times will also be independently distributed. Hence, the reliability of the assembly line will be given by $R_{A L}=\prod_{j=1}^{N} R_{j}$. Therefore, failure rate of the assembly line will be the sum of the failure rates of the individual workstations. Our objective is to ensure high reliability value for assuring high stability in the system. Unfortunately, this may demand for high idle time in the system for each workstation, which may in turn increase cycle time. This is undesirable and to avoid the same we need to impose restriction in terms of cycle time. Our objective is to maximize the rate of production, i.e., minimize the cycle time.

\subsection{Mathematical formulation}

Let us consider the binary variable $a(i, j)$ such that 
$a(i, j)=\left\{\begin{array}{cc}1 & \text { if } i \in W_{j} i \text { th task is assigned to } W_{j}, \\ 0 & \text { otherwise }\end{array} \quad i=1, \cdots, K, j=1, \cdots N\right.$.

The following condition must hold for each $i=1,2, \ldots . ., K$, under the restriction that the $\mathrm{i}^{\text {th }}$ task can be assigned to one and only one workstation,

$\sum_{j=1}^{N} a(i, j)=1$

Further, according to precedence constraints if task $i^{\prime}$ is to be assigned before assigning task $i$, (symbolically $i^{\prime}<i$ ) then

$a(i, j) \leq \sum_{r=1}^{j} a\left(i^{\prime}, r\right) \quad \forall i^{\prime} \prec i$.

Since the task times are independent random variables, the condition for completion of tasks in a workstation within the assigned cycle time can be best described in terms of chance measure,

$R_{j}=\operatorname{Pr}\left[\sum_{i=1}^{K} t_{i} a(i, j) \leq C\right], \quad j=1, \cdots N$.

For the calculation of reliability, we need to make distributional assumption for elemental times.

The objective of our proposed method is to increase productivity by minimizing cycle time c subject to precedence constraints and overall reliability constraint. Thus, the optimization framework of the line balancing problem can be expressed in terms of the following:

$\min c$

(i)

subject to

$$
\sum_{j=1}^{N} a(i, j)=1
$$

$\forall i$

$$
a(i, j) \leq \sum_{r=1}^{j} a\left(i^{\prime}, r\right)
$$

$$
\forall i^{\prime} \prec i
$$

(iii) $\quad R_{A L} \geq 1-\alpha$

(iv) $\quad a(i, j)=0,1$

$\forall i, j$

(v) $\quad c \geq \max p_{i}$

This is a mixed integer programming problem with stochastic constraints and cannot be solved by any standard method. As a result, the above formulation requires development of a solution technique. We present an algorithm in response to the above requirement.

\section{The Algorithm}

1. Set the desired level of Reliability of the assembly line at $(1-\alpha)$,

First, set the cycle time at $C_{S}=p_{i(\max )}$, where $p_{i(\max )}$ is the highest mean task time among the $K$ tasks.

2. Let, cycle time $c=c_{S}$,

3. Prepare the list of all unvisited tasks - call it list U,

4. Prepare list $\mathrm{Y}$ from the list $\mathrm{U}$ with no immediate predecessor or whose immediate predecessors have been visited. The tasks of $\mathrm{Y}$ are ready for selection,

5. Prepare list A from the list $\mathrm{Y}$ having assembly time less than that of trial cycle time and is allowable for inclusion,

6. Randomly select a task form list A and reset the cycle time $\{c-$ assemble time $\}$,

7. If cycle time is less than the assemble time, then open a new workstation. Reinitialize cycle time to its original value and repeat the above steps until all nodes are visited, 
8. After a complete allocation of tasks to workstations, calculate the Reliability $\left(R_{A L}\right)$ of the assembly line,

9. After each run, the reliability $R_{A L}$ is compared with the desired reliability of the assembly line $(1-\alpha)$. If the $R_{A L} \geq(1-\alpha)$ go to step 11 , Otherwise repeat step 3 to $9 \mathrm{M}$ times, where $\mathrm{M}$ is the number of simulated trials,

10. If $R_{A L}$ value does not cross $(1-\alpha)$ value increase $c$ by one go to step 3 ,

11. Print the $c$ value, this cycle time is the minimum value of cycle time $\left(c_{o}\right)$ for which the assembly line has given the desired level of reliability.

12. For that particular $c_{o}$ value, repeat step 3 to $9 \mathrm{M}$ times, where $\mathrm{M}$ is the number of simulated trials. Find the maximum value of $R_{A L}$ among those $R_{A L}$ values. The allocation plan corresponding to the maximum $R_{A L}$ value is the final solution to the problem.

To make this algorithm functional, we have to assume distributional model for each element. Under the gamma distribution for each task time, it is easy to note from the reproductive property of the gamma distribution that the workstation time will also follow gamma distribution. Since $p_{i}$ is the parameter of the $i^{\text {th }}$ task time, $\sum p_{i} a(i, j)$ will be the parameter (also mean) of the gamma distribution of the $j^{\text {th }}$ workstation. Hence, we can write

$$
R_{j}=\frac{1}{\Gamma\left(\sum p_{i} a(i, j)\right)} \int_{0}^{c} e^{-x} x^{\sum p_{i} a(i, j)} d x
$$

Thus, in terms of incomplete gamma function we have,

$$
R_{j}=\Gamma\left(\sum p_{i} a(i, j), c\right)
$$

Then the reliability of the assembly line, $\mathrm{R}_{\mathrm{AL}}$, can be expressed as,

$R_{A L}=\prod_{j=1}^{N} \Gamma\left(\sum p_{i} a(i, j), c\right)$,

following the properties of the series system and the fact that workstations are arranged in series.

Similar studies can be carried out under other distributional model.

\section{Worked out example}

Let us consider a famous problem studied in Wild (2004) under the deterministic setup. We have adopted it under stochastic setup for the purpose of explaining how the proposed formulation works. Fig. 1 represents an assembly line balancing problem. The numerical figure within a circle represents the task number.

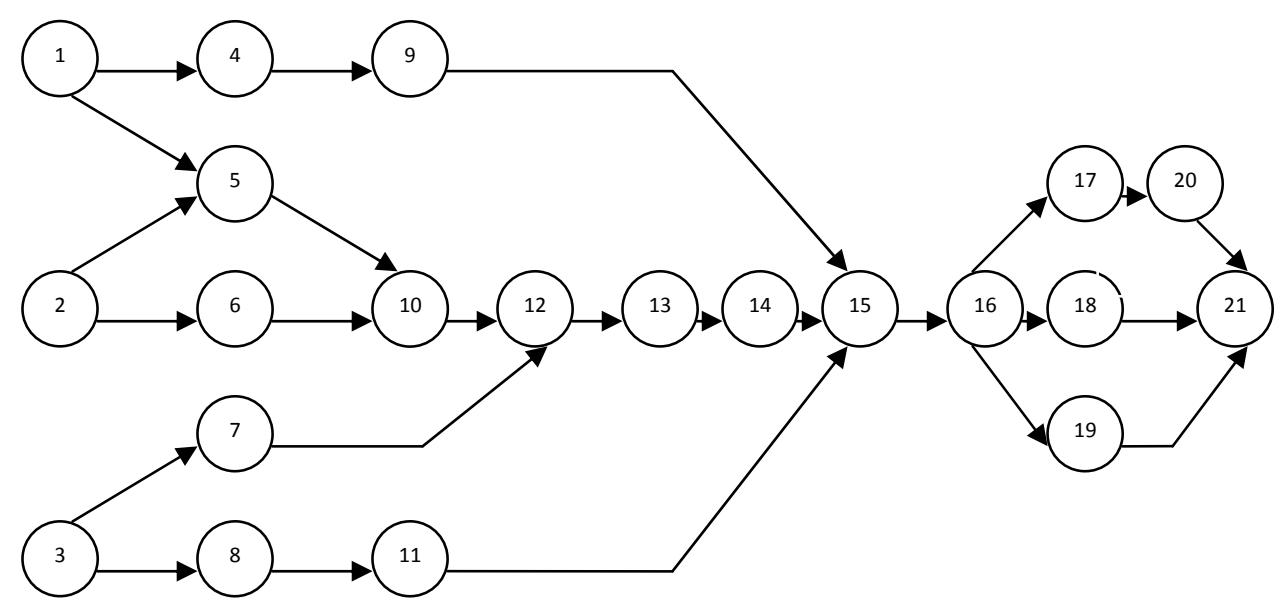

Fig. 1. Precedence diagram of workstations 
In Table 1, the above mentioned problem is summarized in terms of work elements, immediate predecessor(s), and expected task durations.

\section{Table 1}

Precedence relation and expected task times of work elements

\begin{tabular}{llllllllllllllllllllll}
\hline Work Element & 1 & 2 & 3 & 4 & 5 & 6 & 7 & 8 & 9 & 10 & 11 & 12 & 13 & 14 & 15 & 16 & 17 & 18 & 19 & 20 & 21 \\
\hline $\begin{array}{l}\text { Immediate } \\
\text { Predecessor }\end{array}$ & - & - & - & 1 & 1,2 & 2 & 3 & 3 & 4 & 5,6 & 8 & 7,10 & 12 & 13 & $9,11,14$ & 15 & 16 & 16 & 16 & 17 & $18,19,20$ \\
$\begin{array}{l}\text { Expected } \\
\text { Activity Time }\end{array}$ & 6 & 5 & 8 & 9 & 5 & 4 & 5 & 6 & 10 & 5 & 6 & 2 & 4 & 4 & 12 & 10 & 5 & 15 & 10 & 5 & 6 \\
\hline
\end{tabular}

We assume gamma distribution for each independently distributed elemental time and apply the algorithm suggested herein. The final solution is presented in Table 2 with optimum cycle time 27 time units with a minimum expected slackness of 12 time units. There are 11 workstations in the final solution. The attained reliability of the complete line is 0.967737 . Corresponding expected balancing loss has been calculated according to the following formula

$$
E(B)=\frac{\left(N C-\sum p_{i}\right)}{N C} * 100 \%
$$

The expected balancing loss comes out as $51.85185 \%$.

Table 2

Final Optimum Configuration with more than 95\% reliability

\begin{tabular}{llllllllllll}
\hline WorkStation & 1 & 2 & 3 & 4 & 5 & 6 & 7 & 8 & 9 & 10 & 11 \\
\hline Work Elements & 3,2 & 1,8 & $5,6,7$ & $10,11,12$ & 13,14 & 9,14 & 15 & 16,17 & 19,20 & 18 & 21 \\
\hline
\end{tabular}

\section{Conclusion}

The objective of this work is to develop a stable/reliable solution for any assembly line balancing problem. For this purpose, we have proposed a new variant of assembly line and we referred it as Type-3 Simple assembly line balancing problem or SALBP-3. This framework aims at achieving a balanced distribution of work elements among different work stations; provide a desired level of reliability for the entire setup and simultaneously ensure minimum cycle time without violating precedence constraints. The concepts of trial cycle time, slack time in addition to cycle time have been introduced to obtain the optimum solution.

In view of the stochastic variations in the task times resulting in stochastic setup for the balancing problem, we expect that this reliability consideration for the determination of the optimum configuration will come out as an important measure of efficiency. Ensuring desired level of reliability will be the main task for an assembly line balancing planner and our proposed algorithm may serve as an appropriate tool.

\section{References}

Agarwal, S. and Tiwari, M. K. (2008). A collaborative ant colony algorithm to stochastic mixedmodel U-shaped disassembly line balancing and sequencing problem. International Journal of Production Research, 46(6), 1405-1429.

Amasaka, K. and Sakai, H. (1996). Improving the reliability of body assembly line equipment. International Journal of Reliability, Quality and Safety Engineering, 3(1), 11-24.

Berger, I., et al. (1992). Branch-and-bound algorithms for the multi-product assembly line balancing problem. European Journal of Operations Research, 168, 694-715.

Bowman, E.H. (1960). Assembly Line Balancing by Linear Programming. Operations Research, 8(3), 385-389.

Bryton, B. (1954). Balancing of a continuous production line. M.Sc.Thesis, North-Western University. 
Bukchin, Y. and Rabinowitch, I. (2006). A branch-and-bound based solution approach for the mixedmodel assembly line-balancing problem for minimizing stations and task duplication costs. European Journal of Operational Research, 174, 492-508.

Charlton, J.M. \& Death, C.C. (1969). A general method for Machine scheduling. International Journal of Production Research, 7, 207.

Chernyi, A. G. (2007 ). Probabilistic analysis of the performance of a synchronous assembly line. Russian Engineering Research, 27(4), 199-201.

Erel, E., Sabuncuoglu, I. and Sekerci, H. (2005). Stochastic assembly line balancing using beam search. International Journal of Production Research, 43(7), 1411-1426.

Gamberini, R., Gebennini, E., Grassi, A. and Regattieri, A. (2009). A multiple single-pass heuristic algorithm solving the stochastic assembly line rebalancing problem. International Journal of Production Research, 47(8), 2141-2164.

Geoffrion \& Arthur M. (1976). The purpose of mathematical programming is insight, not numbers. Interface, 7(1), 81-92.

Grabau, M.R., Maurer, R.A., \& Ott., D.P. (1997). Using Simulation to Generate the Data to Balance an Assembly Line. In Proceeding of the 1997 Winter Simulation Conference, WSC '97, Atlanta, GA, December 7-10, 733-738.

Graves, S.C. \& Lamer, B.W. (1983). An integer programming procedure for assembly system design problems. Operations Research, 31, 522-545.

Gu, L., Hennequin, S., Sava, A. and Xie, X (2007) Assembly line balancing problem solved by estimation of distribution. Automation science and Engineering, IEEE International Conference.

Helgerson, N.B. \& Birnie, D.P. (1961). Assembly Line balancing using the ranked positional weight technique. Journal of Industrial Engineering, 11(6), 394.

Hoffmann, T.R. (1963). Assembly line balancing with precedence matrix. Management Science, 9, 551-562.

Kilbridge, K. \& Wester, L. (1961). A heuristic method of assembly line balancing. Journal of Industrial Engineering, 11(4), 292.

Mansoor, E.M. \& Yadin, M. (1971). On the problem of assembly line balancing. Development in Operations Research, edited by B. Avi-ltzhak, Gordon and Breach, New York, 361.

Mansoor, E.M. (1968). Assembly line balancing: A heuristic algorithm for variable operator performance levels. Journal of Industrial Engineering, 19, 618.

Moodie, C.L. \& Young, H.H. (1965). A heuristic method of assembly line balancing assumptions of constant or variable work element times. Journal of Industrial Engineering, 16, 23-29.

Nevins, A.J. (1972). Assembly Line Balancing using Best Bud search. Management Science, 18(9), 530.

Nicosia et al. (2002). Optimally balancing assembly lines with different workstations. Discrete Applied Mathematics, 118, 99-113.

Pinnoi, A. and Wilhelm, W.E. (1998). Assembly system design: A branch and cut approach. Management Science, 44, 103-118.

Roy, D. \& Khan, D. (2010). Assembly line balancing to minimize balancing loss and system loss. Journal of Industrial Engineering International, 6(11), 1-5.

Roy, D. \& Khan, D. (2011a). Optimum assembly line balancing: A stochastic programming approach. International Journal of Industrial Engineering Computation, 2(2011), 329-336.

Roy, D. \& Khan, D. (2011b). Optimum assembly line balancing by minimizing balancing loss and a range based measure for system loss. Management Science Letters, 1(2011), 13-22.

Salveson, M.E. (1955). The assembly line balancing problem. Transaction of American Society of Mechanical Engineering, 939.

Sarin, S. C., \& Erel, E. (1990). Development of cost model for the single-model stochastic assembly line balancing problem. International Journal of Production Research, 28(7), 1305-16.

Scholl, A. (1999). Balancing and Sequencing of Assembly Lines. $2^{\text {nd }}$ Edition, Physica-verlag Heidelberg, ISBN 3-7908-1180-7. 
Suhail, A. (1983). Reliability and optimization considerations in a conveyor-paced assembly line system. International Journal of Production Research, 21(5), 627 - 640.

Suresh, G. \& Sahu, S. (1994). Stochastic assembly line balancing using simulated annealing. International Journal of Production Research, 32(8), 1801-1810.

Wild, R. (2004). Operation Management. Thomson, Singapore.

Zhao, X., Yeung, J.H.Y. and Xie, J. (2006). Sequence-to-customer goal with stochastic demands for a mixed-model assembly line. International Journal of Production Research, 44(24), 5279-5305. 